\title{
Originals
}

\section{Physical and psychological health of children of Type 1 (insulin-dependent) diabetic mothers}

\author{
D. R. Hadden ${ }^{1,3}$, E. Byrne ${ }^{3}$, I. Trotter ${ }^{1}$, J. M.G. Harley ${ }^{1}$, G. McClure ${ }^{2}$ and R. R. McAuley ${ }^{4}$ \\ ${ }^{1}$ Diabetes Pregnancy Clinic, ${ }^{2}$ Neonatal Nursery, The Royal Maternity Hospital, ${ }^{3}$ Diabetic Clinic, Royal Victoria Hospital and \\ ${ }^{4}$ Child Psychiatric Department, Royal Belfast Hospital for Sick Children, Belfast, Northern Ireland
}

\begin{abstract}
Summary. No difference was found at paediatric assessment, or by a psychologically-based maternal and teacher questionnaire of the emotional state or academic achievement, between 123 children of Type 1 (insulin-dependent) diabetic mothers and 124 children of non-diabetic mothers. The groups were closely matched for maternal age, sex and posi-
\end{abstract}

tion in sibship of the child, and age and home environment of the mother. The children of diabetic mothers had all been delivered before week 38 of gestation.

Key words: Emotional and academic achievement, children of diabetic mothers, Type 1 diabetes.
There is some uncertainty in published data on the possible prevalence of minor cerebral dysfunction in children born to mothers who were diabetic during pregnancy. The present study was prompted by the report of Yssing [1], who had followed up 749 surviving children born to insulin-treated diabetic mothers in Copenhagen between 1946-1966 and found a high incidence of children $(36 \%)$ with evidence of "minor cerebral dysfunction". About half of these affected children had minor deviations from normal, for example, developmental disorders of language (9\%), enuresis $(9 \%)$, behavioural problems $(10 \%)$ and reading difficulties (10\%). In Aberdeen, Reid and Russell [2] followed up 127 children born between 1962-1974 to mothers with gestational diabetes treated in three different ways. They assessed the intellectual and neurological status among other variables, and found no significant impairment in any of the three groups.

Neither of these studies incorporated a control group, which would be an important part of a survey designed to detect minor deviations from normality. As the Danish results did not seem to match the experience in Northern Ireland during the same period [3-5], the present study was initiated to compare the health and intellectual ability of children of diabetic mothers with that of a matched control group of children of non-diabetic mothers. This study was based on the experience of a large-scale investigation of childhood behaviour and mental health carried out in Buckinghamshire, England [6].

\section{Methods}

\section{Patient selection}

A total of 174 viable pregnancies of Type 1 (insulin-dependent) diabetic mothers were identified from the records of the antenatal diabetic clinic at the Royal Maternity Hospital, Belfast, for births between 1963-1976. There had been 22 perinatal deaths during the selected period. Of the 152 survivors, two had been adopted and were not further identified. It was not possible to find a current address for a further 12 mothers, leaving 138 study pregnancies for matching. One hundred and thirty-eight pregnancies in non-diabetic mothers were then selected from the records of the same hospital. The initial matching procedure was to identify for each study pregnancy, regardless of outcome, up to three control pregnancies fulfilling the following criteria: (1) date of delivery less than one month before or after that of the study pregnancy; (2) mother's age within one year of that of the mother of the study pregnancy; (3) same sex of child; (4) same sibship position of child; (5) similar home environment - city or country address at time of the pregnancy; (6) similar social class - identified from occupation of father.

Pregnancies were not prospectively matched for gestational age of the child, birth weight, method of delivery or the presence of complications of pregnancy or the neonatal period. At that time the obstetric policy for diabetic pregnancy was to aim for delivery by 38 weeks, and the Caesarean section rate was over $50 \%$.

The parents of the 138 study children were then asked by letter if they were willing to take the child to the Royal Maternity Hospital for one day for a follow-up assessment, to include a questionnaire interview and an examination by a consultant paediatrician. One hundred and twenty-three parents/children attended during 1980. As soon as a study interview/examination was completed, the first of the three selected control mothers was sent a similar letter explaining the nature of the study and that they had been selected as a normal or control group, and asking them to attend with their child for a questionnaire interview and medical examination. There was a good response to the 
Table 1. Birth weight by gestational age in the children of 125 diabetic mothers and 125 matched non-diabetic mothers

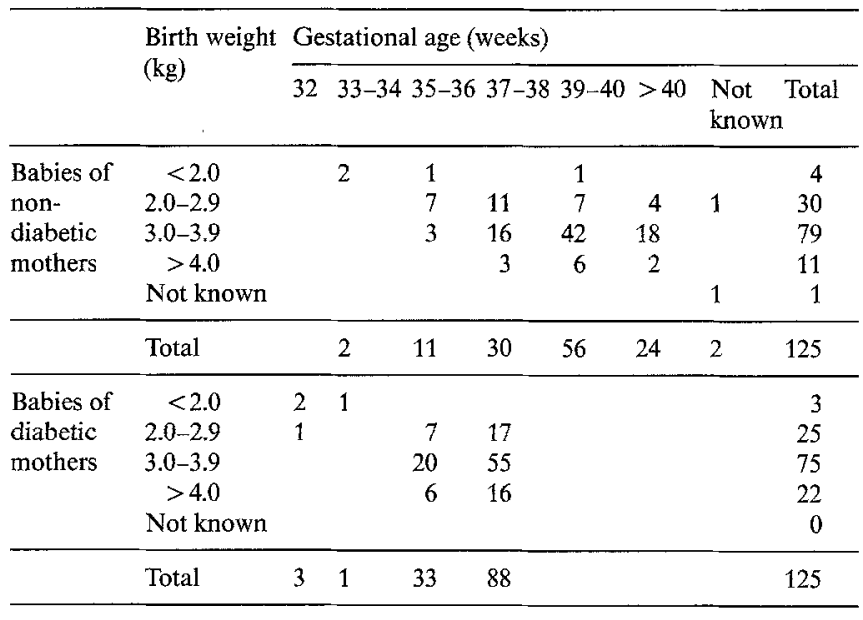

Table 2. Mean 2-hour post-prandial venous plasma glucose values and mean insulin dose in 125 diabetic mothers in relation to the pregnancy

\begin{tabular}{|c|c|c|c|}
\hline & \multicolumn{3}{|c|}{ Distribution of mean plasma glucose } \\
\hline & $\begin{array}{l}\text { Year before } \\
\text { pregnancy }\end{array}$ & $\begin{array}{l}\text { During preg- } \\
\text { nancy }\end{array}$ & $\begin{array}{l}\text { Year after } \\
\text { pregnancy }\end{array}$ \\
\hline \multicolumn{4}{|c|}{$\begin{array}{l}\text { Maternal 2-h } \\
\text { post-prandial } \\
\text { venous plasma } \\
\text { glucose } \\
(\mathrm{mmol} / \mathrm{l})^{\mathrm{a}}\end{array}$} \\
\hline$<5.5$ & 11 & 8 & 7 \\
\hline $5.5-8.3$ & 32 & 98 & 30 \\
\hline $8.4-11.1$ & 32 & 15 & 54 \\
\hline$>11.1$ & 24 & 2 & 32 \\
\hline Not known & $(26)$ & $(2)$ & $(2)$ \\
\hline \multicolumn{4}{|c|}{$\begin{array}{l}\text { Maternal in- } \\
\text { sulin dose } \\
\text { (units } / 24 \mathrm{~h} \text { ) }\end{array}$} \\
\hline Nil & 20 & 1 & 12 \\
\hline $10-39$ & 23 & 13 & 30 \\
\hline $40-79$ & 67 & 55 & 72 \\
\hline $80-119$ & 5 & 43 & 8 \\
\hline$>120$ & 7 & 13 & 0 \\
\hline Not known & 3 & 0 & 3 \\
\hline
\end{tabular}

${ }^{\mathrm{a}}$ mean of all values obtained;

${ }^{\mathrm{b}}$ mean of all recorded doses during the time period

initial request, and no difficulty was found in obtaining the desired matched control group. If the first selected control did not wish to attend, the second or rarely the third was requested. Up to six parents/ children attended each review clinic, and approximately equal numbers of the diabetic and control groups were seen each day, although by design each diabetic parent/child attended on a different day from the corresponding matched controls. Totally 'blind' conditions for the medical or questionnaire interviews were not designed as the mother's diabetic condition could not be concealed, but neither the research assistant nor the paediatrician had been part of the clinical care of mother or baby during any of the pregnancies in question.

At the review clinic the child was examined by the consultant paediatrician using a standard technique with special reference to any physical defects. The mother was asked to complete the questionnaire at the clinic, the study research assistant being present to answer ques- tions of interpretation and to ensure completion. Permission was obtained for a teacher questionnaire to be sent to the child's school.

In two instances the child of a diabetic mother was known to have died after the perinatal period, one at 6 months from pneumonia and one at 9 months from gastroenteritis. These pregnancies were not excluded from the 125 in the study group, so only 123 children were potentially available for subsequent study. Equally, one child of a selected control mother was found to have died within 1 week of birth from respiratory distress syndrome. This pregnancy was not excluded from the control group, leaving 124 control children for study.

\section{Data on matching}

There were ultimately 123 children of diabetic mothers and 124 children of control mothers surviving for study.

Matching between the two groups was very close for year of birth (range: 1963-1976) and maternal age at index pregnancy (range: 18-44 years), and exact matching for sex of child and position in sibship (first, second or third, fourth or more) was achieved. Place of birth (town or country) was also very closely matched. Because of the early delivery policy for diabetic pregnancy, matching for birth weight by gestational age was not achieved, Table 1 shows that all children of the diabetic mothers were born before the end of week 38 , whereas 80 of the 125 control children (two not known) were born after week 38 ; 22 of the children of diabetic mothers and only 11 of the control children (one birth weight not known) weighed $4.0 \mathrm{~kg}$ or more at birth. Four of the children of diabetic mothers were delivered before week 35 , and three of these weighed less than $2.0 \mathrm{~kg}$ at birth: only two of the control children were in this category. Comparison of height and weight for age between the two groups of children at the time of the study examination did not reveal any trend.

\section{Diabetic control during the index pregnancy}

For the group of diabetic mothers the average maternal age was 26.1 years (average parity 1.1), the mean hospital booking date 12 weeks. Twenty-six per cent had had a previous miscarriage. During the index pregnancy the following bad prognostic signs were recorded: pyelonephritis (10), severe diabetic ketoacidosis (1), pre-eclampsia (28), neglect of clinical follow-up (5), hypertension (6), retinopathy (8), nephropathy (1), cardiovascular disease (1). Three mothers had had Type 1 diabetes for $<1$ year, 59 for $1-9$ years, 53 for $10-19$ years and 7 for 20 or more years; the date of onset was uncertain for three. The mean maternal insulin doses and the mean maternal plasma glucose levels (calculated from the total number of postprandial venous plasma glucose specimens recorded) for the year before the pregnancy, the duration of gestation and the year after delivery are shown in Table 2 . These data are based on varying numbers of observations for each patient, but the trend shows a considerable improvement in the mean maternal plasma glucose and increased mean insulin dose during the pregnancy.

\section{Non-fatal congenital abnormalities}

The following abnormalities were recorded at the paediatric examination in children of diabetic mothers: central nervous system - spina bifida occulta (1), spastic tetraplegia (1), Erb's palsy (1); cardiovascular system - ventriculoseptal defect (2); skeletal - genu valgum (1); others - undescended testis (1), hypospadias (1), pigmented skin patch (1). In children of control mothers were the following: central nervous system - none; cardiovascular system - ventriculoseptal defect (1); skeletal - pes planus (2); others - undescended testes (2); pigmented skin patch (1).

\section{Questionnaires}

The parent and teacher questionnaires used in this study were constructed and developed in England for use in the Buckinghamshire 
Epidemiological Survey of over 6,000 school-aged children, covering health, behaviour and academic progress. This study is described in detail in the book "Childhood Behaviour and Mental Health" [6], where the full questionnaires are recorded.

The parent questionnaire is divided into three major sections. In Section A the parent is requested to respond with 'yes' or 'no' to 34 separate statements about illness and health problems. The range includes items relating to minor health probiems - "wears glasses", "has difficulty hearing", "has frequent colds", "gets travel sick", and items relating to more serious problems - eczema, asthma, heart trouble, cerebral palsy or diabetes.

In Section B, for each of 37 different behaviour patterns the parent is asked to underlinie the one out of three statements which best describes their child. For example, question 50 relates to school behaviour and the three possible choices include "likes school very much", "likes school about as much as most children" and "dislikes going to school". The range covered includes neurotic behaviour such as fear in a variety of situations, shyness and mood disturbance, anti-social behaviour such as disobedience, destructiveness or lying, and lastly miscellaneous examples such as restlessness, irritability and mannerisms. Only the extreme item of each of the behaviour patterns is reported.

In Section $\mathrm{C}$ the parent is asked to complete a range of questions relating to the family, including the child's background, parental occupation or any prolonged absences of parent or child.

The teacher questionnaire is also divided into three sections. Section $A$ is devoted to school attendance and reasons for absences in the previous school term. Section B gives a rating to the child's reading ability and attainment for age and school based on the teacher's knowledge of school examination performance and general classroom ability. An IQ rating if available is also obtained. In Section C the teacher is asked to underline any of 21 descriptions of minor heaith problems or abnormal behaviour patterns for the particular child.

The parent questionnaire was completed by the parent accompanying the child to the clinic for physical examination. On the same visit permission was requested (and granted in all but three cases) to obtain a school report. When this was given the child's school teacher was contacted and asked to complete the teacher questionnaire.

\section{Response and statistical analysis}

For children aged 5 years and over, 90 parent and 74 teacher questionnaires were completed for the children of diabetic mothers, and 93 and 76 respectively for the control group. For children under 5 years, 29 parent questionnaires were returned for children of diabetic mothers and 30 for the control group.

The data were transferred to punchcards and analysed statistically using the $\chi^{2}$ technique.

\section{Results}

Table 3 lists in descending order of frequency some of the minor health problems which emerged from the questionnaire for the children of diabetic mothers and for control children. For children aged 5 years and over, at least one minor health problem was present in $57 \%$ of the children of diabetic mothers and $62 \%$ of control children. Three or more minor health problems were present in $14 \%$ of the children of diabetic mothers and $16 \%$ of control children. There was no significant difference between these two groups $(p>0.05)$. For children aged 4 years and younger there were minor health problems in $45 \%$ and $40 \%$ of the two groups. Three or more
Table 3. Minor health problems reported on parent questionnaires at the time of review

\begin{tabular}{lll}
\hline & $\begin{array}{l}\text { Children of diabetic } \\
\text { mothers }\end{array}$ & $\begin{array}{l}\text { Control } \\
\text { children }\end{array}$ \\
\hline $\begin{array}{l}\text { Minor health prob- } \\
\text { lems (in order of } \\
\text { frequency) }\end{array}$ & $\begin{array}{l}\text { Frequent colds } \\
\text { Persistent earache } \\
\text { Difficulty hearing } \\
\text { Highly strung } \\
\text { Wears glasses } \\
\text { Sick headaches } \\
\text { Overweight }\end{array}$ & $\begin{array}{l}\text { Frequent colds } \\
\text { Highly strung } \\
\text { Skin trouble } \\
\text { Persistent earache } \\
\text { Difficulty hearing } \\
\text { Travel sickness } \\
\text { Wears glasses }\end{array}$ \\
$\begin{array}{cll}\text { Skin trouble } \\
\text { Faints } \\
\text { Travel sickness }\end{array}$ & $\begin{array}{l}\text { Fints headaches } \\
\text { Overweight }\end{array}$ \\
\hline $\begin{array}{c}\text { Children aged 5years } \\
\text { and older }\end{array}$ & 90 & 93 \\
$\begin{array}{c}\text { Any minor health } \\
\text { problem }\end{array}$ & $52(57 \%)$ & $58(62 \%)$ \\
$\begin{array}{c}\text { Three or more minor } \\
\text { health problems }\end{array}$ & $13(14 \%)$ & $15(16 \%)$ \\
\hline $\begin{array}{c}\text { Children aged 4 years } \\
\text { and younger }\end{array}$ & 29 & 30 \\
$\begin{array}{c}\text { Any minor health } \\
\text { problem }\end{array}$ & $13(45 \%)$ & $12(40 \%)$ \\
$\begin{array}{c}\text { Three or more minor } \\
\text { health problems }\end{array}$ & $1 \quad(3 \%)$ & $3(10 \%)$ \\
\hline
\end{tabular}

Table 4. Behavioural problems reported on parent questionnaires at the time of review

\begin{tabular}{lll}
\hline & $\begin{array}{l}\text { Children of diabetic } \\
\text { mothers }\end{array}$ & $\begin{array}{l}\text { Control } \\
\text { children }\end{array}$ \\
\hline $\begin{array}{ll}\text { Behavioural prob- } \\
\text { lems (in order of } \\
\text { frequency) }\end{array}$ & $\begin{array}{ll}\text { Irritable } \\
\text { Restless }\end{array}$ & $\begin{array}{l}\text { Fussy with food } \\
\text { Restless }\end{array}$ \\
& Restless in sleep & Complains \\
& Fussy with food & Eating difficulty \\
& Crying & Irritable \\
& Difficulty learning & Nail bites \\
Moody & Moody \\
& Complains & Difficulty learning \\
& Nail bites & Disobedient \\
& Tantrums & Tantrums \\
& Daydreams & Daydreams \\
& Eating difficulty & Crying \\
& Disobedient & Restless in sleep \\
& (Telling lies, stealing, playing truant, poor \\
& bowel control, quarrelling and mannerisms \\
& were very infrequent in both groups). \\
\hline
\end{tabular}

Children aged 5 years 90

93

and over

Mean number of be- 2.4

2.1

havioural problems

per child

Children with 4 or $19(21 \%) \quad 15(15 \%)$

more behavioural

problems

Children aged 4 years 29

and younger

Children with 4 or $\quad 9(31 \%) \quad 12(40 \%)$

more behavioural

problems 
Table 5. School attendance: number missing 10 or more days in last school term

\begin{tabular}{lcl}
\hline $\begin{array}{l}\text { Reason } \\
\text { for absence }\end{array}$ & $\begin{array}{l}\text { Children of diabetic } \\
\text { mothers }(n=74)\end{array}$ & $\begin{array}{l}\text { Control children } \\
(n=76)\end{array}$ \\
\hline Sickness of child & 8 & 5 \\
No good reason & 3 & 1 \\
Hospital visit by child & 1 & 1 \\
Parent illness & 1 & 1 \\
Other reasons & 1 & 0 \\
\hline Total & $14(19 \%)$ & $8(11 \%)$ \\
\hline$\chi^{2}=285 ; \mathrm{NS}$ & &
\end{tabular}

$\chi^{2}=2.85 ; \mathrm{NS}$

Table 6. Teachers' rating: academic ability (based on assessment of reading ability and school examinations)

\begin{tabular}{lll}
\hline & $\begin{array}{l}\text { Children of diabetic } \\
\text { mothers }(n=74)\end{array}$ & $\begin{array}{l}\text { Control children } \\
(n=76)\end{array}$ \\
\hline Above average & $18(24 \%)$ & $31(41 \%)$ \\
Average & $37(53 \%)$ & $32(42 \%)$ \\
Below average & $17(23 \%)$ & $13(17 \%)$ \\
\hline
\end{tabular}

$\chi^{2}=4.8 ; \mathrm{NS}$

minor health problems were present in $3 \%$ and $10 \%$ respectively $(p>0.05)$.

Some of the aspects of behaviour reported for the children aged 5 years and over are shown in Table 4 , again listed in descending order of frequency for each group. The mean number of behavioural problems per child was 2.4 per child of a diabetic mother and 2.1 per child in the control group. Twenty-one percent and 15\% respectively had four or more problems $(p>0.05)$. For children aged 4 years or younger, there were four or more behavioural problems in $31 \%$ of the children of diabetic mothers and $40 \%$ of the controls $(p>0.05)$.

From the teacher questionnaires, 14 of the children of a diabetic mother and eight of the control children had missed 10 or more days in the last school term $(p>0.05$; Table 5). When the reasons for absence were analysed, only one child of a diabetic mother and one control child had been off school because of parental illness. The teachers' rating of academic ability (Table 6) also showed no significant difference between the two groups. Seventy-seven percent of the children of diabetic mothers were considered to be average or above average compared with $85 \%$ of the controls.

\section{Discussion}

It is difficult to define precisely where and when a concept arose that children born to mothers diabetic when pregnant might be subject to long-term developmental problems in childhood. Yssing [1] produced a major retrospective study of 740 children born between 1946 and 1966 at the Diabetic Centre, Rigshospitalet, Copenhagen, and surviving the neonatal period, with age at fol- low-up from 1 $1 \frac{1}{2}-26$ years: her paediatric assessment was that only $52 \%$ of these children were completely normal, $26 \%$ had minor deviations from normal and $22 \%$ had major abnormalities.

The problems of perinatal mortality and congenital malformations are well established and are not analysed further in this report; the Belfast experience is not different from that of other specialist centres. It is not the purpose of this paper to discuss the actual management of pregnancy in a diabetic mother, nor the problems associated with the use of the perinatal mortality as an indicator of successful outcome of the pregnancy. The overall perinatal mortality for the diabetic pregnancies between 1963 and 1976 was $12.6 \%$. Previous publications from this centre [3-5] have analysed the reasons for the fall in perinatal mortality from about $20 \%$ to below $5 \%$ during that period, in the context of a steadily falling perinatal mortality rate for the whole population of the UK and for the hospital. Although there is now much more general acceptance of the need for very intensive blood glucose control during diabetic pregnan$c y$, it has in fact been the policy of this clinic to strive for such good control with frequent measurement of venous plasma glucose throughout the study period, which produced the data in Table 2. Self-monitoring of capillary blood glucose became available after 1976, and has made possible a further improvement.

In this study, among the children of diabetic mothers there were four major and five minor congenital abnormalities at the paediatric assessment, and among the control children one major and six minor congenital anomalies. No cases of juvenile-onset Type 1 diabetes were found in either study or control children. The Copenhagen data, although based on a long experience and larger numbers, suffer from the absence of a control group. The major cerebral dysfunctions (cerebral palsy and epilepsy) were more than twice as prevalent as expected in the Danish population, but mental retardation and febrile convulsions were of equal prevalence. Yssing states that "slightly more children than would be expected" had minor developmental distrubances such as language disorders, enuresis or behavioural problems, and that these were very often in combination and more common in males [1]. She quotes prevalences of about $10 \%$ for each of these disturbances.

The Belfast data are not directly comparable but clearly show that there is no overall difference between the children of diabetic mothers and the control children in relation to a standardized assessment of childhood behaviour and mental health. However, this must be considered a preliminary report, and caution should be exerted before drawing firm conclusions. There were several trends, not reaching statistical significance, beyond 4 years of age in the children of diabetic mothers. These children appeared to miss school and to have a somewhat lower academic achievement on teachers' assessment than the control group. While the groups were matched for age, sex, social class and area of abode, it is 
just possible that variables other than having a diabetic mother might explain these trends. Family size or marital stability might be involved. Initial assessment does not reveal any relationship between maternal blood glucose or insulin dose in pregnancy and the behavioural problems studied.

The Aberdeen study [2] is not comparable as the authors carried out only a simple neurological assessment on children of mothers who would be classified as gestational, or temporary, non-insulin-dependent diabetic. This simple classification did not show any trend between children of groups of mothers treated with chlorpropamide, insulin or diet alone. It is of interest, however, that teachers' ratings of the childrens' academic ability were obtained in Aberdeen, and can be superficially compared with results of the Belfast study and also for those in the large group of 5803 children assessed in the Buckinghamshire study. There was no difference between the numbers rated average in any of the groups (range $42 \%-53 \%$ ): the control children in Belfast achieved the highest above-average rating (41\%), compared with $24 \%$ for the Belfast children of diabetic mothers and $21 \%$ for the Buckinghamshire study.

In conclusion, a local enquiry, in a defined population of pre-school and school-age children, of the nature and prevalence of several types of conduct commonly believed to indicate emotional disorder, has not indicated any relationship to the presence of maternal diabetes or its medical or obstetrical management during the relevant pregnancy. If the policy of early delivery and more frequent Caesarean section, and the known risks of prematurity, pre-eclampsia and placen- tal insufficiency in diabetic pregnancy have any role at all in connection with subsequent neurological and psychological development of the child, its ascertainment would require a larger study than that possible in one centre.

\section{References}

1. Yssing M (1975) Long-term prognosis of children born to mothers diabetic when pregnant. In: Camerini-Davalos RA, Cole HS (eds) Early diabetes in early life. Academic Press, New York, pp 575-586

2. Reid JA, Russell G (1979) Qualitative assessment of children of known gestational diabetic mothers. In: Sutherland HW, Stowers JM (eds) Carbohydrate metabolism in pregnancy and the newborn. Springer-Verlag, Berlin, pp 462-477

3. Montgomery DAD, Harley JMG (1977) Endocrine disorders in pregnancy. Clin Obstet Gynaecol 4:339-370

4. Glasgow ACA, Harley JMG, Montogmery DAD (1979) Congenital malformations in infants of diabetic mothers. Ulster Med J 48: 109-117

5. Hadden DR (1980) Screening for abnormalities of carbohydrate metabolism in pregnancy 1966-1977: the Belfast experience. Diabetes Care, 3: 440-446

6. Shepherd M, Oppenheim B, Mitchell S (1971) Childhood behaviour and mental health. University of London Press, London, pp 211-222

Received: 18 August 1983

and in revised form: 16 January 1984

Dr. David R. Hadden

Metabolic Unit

Royal Victoria Hospital

Belfast BT12 6BA

Northern Ireland 